(2) Open Access Full Text Article

\title{
Human gastric biopsy-derived lactobacilli suppress Helicobacter pylori-induced interleukin-8 production from gastric epithelial cells in vitro
}

This article was published in the following Dove Press journal:

International Journal of Interferon, Cytokine and Mediator Research

7 May 2011

Number of times this article has been viewed

\author{
Wimonrat Panpetch' \\ Thien Thiraworawong' \\ Somying Tumwasorn ${ }^{2}$ \\ 'Interdisciplinary Program \\ of Medical Microbiology, Graduate \\ School, Chulalongkorn University, \\ Bangkok, Thailand; ${ }^{2}$ Department of \\ Microbiology, Faculty of Medicine, \\ Chulalongkorn University, \\ Bangkok, Thailand
}

Correspondence: Somying Tumwasorn Department of Microbiology, Faculty of Medicine, Chulalongkorn University, Bangkok 10330, Thailand Tel +66 22564l 32

Fax +66 22525952

Email somying.t@chula.ac.th
Abstract: In this report we evaluate the anti-inflammatory effect of a variety of Lactobacillus spp. isolated from human gastric biopsies of dyspeptic patients. These lactobacilli were previously shown to secrete factors that inhibit tumor necrosis factor production from human monocytoid cells in vitro. Conditioned media from these lactobacilli were tested for the ability to modulate Helicobacter pylori-induced interleukin-8 (IL-8) production in AGS gastric epithelial cells. Out of 26 Lactobacillus spp. isolated from urease-negative patients thought not to harbor H. pylori, five significantly inhibited IL-8 production. The IL-8-inhibitory lactobacilli were identified as L. casei or L. paracasei, L. plantarum, L. rhamnosus, and L. salivarius and had no antagonistic effects on $H$. pylori growth. Our findings suggest potential candidates of Lactobacillus for further investigation of their beneficial effects on $H$. pylori-infected patients.

Keywords: Lactobacillus, Helicobacter pylori, interleukin-8, stomach, gastric biopsy, probiotics

\section{Introduction}

Helicobacter pylori is a Gram-negative bacterial pathogen that infects the stomach of humans worldwide. Persistent infection with $H$. pylori results in a gastric inflammatory response, leading to the development of gastroduodenal diseases like chronic atrophic gastritis, gastric and duodenal ulcers, and gastric cancer. ${ }^{1,2} H$. pylori infection induces the production of several inflammatory mediators, including interleukin-8 (IL-8), ${ }^{3-5}$ which is a potent neutrophil chemotactic and activating agent ${ }^{6,7}$ and is associated with disease severity. ${ }^{8,9}$

Less than $80 \%$ of $H$. pylori infections are eradicated with standard triple therapy, ${ }^{10-12}$ and the eradication rate is less than $60 \%$ if clarithromycin-resistant $H$. pylori is present. ${ }^{13,14}$ Even with more aggressive therapy, cases of clarithromycin-resistant H. pylori continue to result in unsatisfactory eradication rates. ${ }^{15}$ A potential solution to declining eradication rates of $H$. pylori infection is the administration of probiotic organisms. Others have demonstrated probiotics to be useful adjuncts in the treatment of $H$. pylori infection, resulting in higher eradication rates, reduction of severity and activity of gastritis, and reduction of antibiotic-associated side effects. ${ }^{16,17}$

We previously isolated lactobacilli from gastric biopsies of dyspeptic patients and demonstrated their immunomodulatory activity against tumor necrosis factor (TNF) production from lipopolysaccharide (LPS)-activated THP-1 monocytoid cells. ${ }^{18}$ In this study, we investigated whether human stomach-derived Lactobacillus spp. can modulate IL-8 production from $H$. pylori-stimulated AGS gastric epithelial cells. 


\section{Materials and methods}

\section{Bacterial strains, culture conditions, and preparation of Lactobacillus- conditioned media}

Lactobacillus spp. were routinely grown on de Man, Rogosa, Sharpe (MRS) agar (Becton Dickinson, Sparks, MD) anaerobically $\left(10 \% \mathrm{CO}_{2}, 10 \% \mathrm{H}_{2}\right.$, and $\left.80 \% \mathrm{~N}_{2}\right)$ in an anaerobic chamber (Concept Plus, Ruskinn Technology Ltd, Bridgend, $\mathrm{UK}$ ) at $37^{\circ} \mathrm{C}$. Lactobacillus-conditioned media (LCM) were prepared as previously described.$^{19}$ Briefly, lactobacilli were cultured as stated previously for 24 hours. The optical density of each culture was determined at $600 \mathrm{~nm}\left(\mathrm{OD}_{600}\right)$ by spectrophotometery (Bio-Rad Smart Spec ${ }^{\mathrm{TM}}$ Plus, Bio-Rad Laboratories Inc, Hercules, $\mathrm{CA}$ ), adjusted to an $\mathrm{OD}_{600} 0.1$ in MRS broth, and cultured as stated previously for 48 hours. Culture supernatant was collected by centrifugation at $4000 \times \mathrm{g}$ for 10 minutes at $4^{\circ} \mathrm{C}$, and the collected supernatant was filtered through a $0.22 \mu \mathrm{m}$ filter (Minisart, Sartorius Stedim Biotech GmbH, Goettingen, Germany). Filtered supernatant was concentrated in a Savant SpeedVac (Savant instruments, Farmingdale, NY) and then resuspended in an equal volume of RPMI 1640 medium (Gibco-Invitrogen, Carlsbad, CA) for further testing with AGS cells. The conditioned media were stored at $-20^{\circ} \mathrm{C}$ until further analysis.

H. pylori ATCC 43504 was grown on Columbia blood agar (Oxoid, Hampshire, UK) supplemented with 7\% (v/v) horse serum (Gibco New Zealand Ltd, Auckland, New Zealand) and $7 \%(\mathrm{v} / \mathrm{v})$ sheep blood at $37^{\circ} \mathrm{C}$ for 48 hours under microaeorphilic conditions $\left(6-12 \% \mathrm{O}_{2}, 5-8 \% \mathrm{CO}_{2}\right)$ using MGC Anaero Pack-Micro Aero boxes (Mitsubishi Gas Chemical Company, Inc, New York, NY). Bacterial cells were then transferred to, and resuspended in, antibioticfree RPMI medium. The bacterial suspension was adjusted to the density of No. 6 McFarland standard and used in the coculture assay.

\section{THP-I monocytoid cell culture and bioassay for TNF activity}

Monocytoid cell culture and in vitro bioassays were performed as stated previously. ${ }^{18}$ Briefly, THP-1 human monocytoid cells (ATCC TIB- 202, Manassas, VA) were maintained in RPMI 1640 medium supplemented with $10 \%$ heat-inactivated fetal bovine serum (Gibco-Invitrogen) in 96-well flat-bottomed tissue culture plates (Nunclon D, Roskilde, Denmark) and incubated at $37^{\circ} \mathrm{C}$ in a humidified $5 \% \mathrm{CO}_{2}$ incubator. THP- 1 cells $\left(2.5 \times 10^{5}\right.$ cells $\left./ \mathrm{mL}\right)$ were incubated with conditioned media $(5 \% \mathrm{v} / \mathrm{v})$ alone or in combination with purified LPS (100 ng/mL) from Escherichia coli serotype O127:B8
(Sigma-Aldrich, St Louis, MO) for 3.5 hours at $37^{\circ} \mathrm{C}$. Supernatants were collected from individual wells by centrifugation at $4^{\circ} \mathrm{C}$ and assayed for TNF with human TNF-specific sandwich quantitative enzyme-linked immunosorbent assay (DuoSet, R\&D Systems, Minneapolis, MN) according to the manufacturer's instructions.

\section{AGS gastric epithelial cell culture}

AGS human gastric adenocarcinoma epithelial cells (ATCC CRL-1739) were obtained from the American Type Culture Collection (Manassas, VA). AGS cells were cultured as a monolayer ( $>80 \%$ confluence) in RPMI 1640 medium supplemented with $10 \%(\mathrm{v} / \mathrm{v})$ heat-inactivated fetal bovine serum (Gibco-Invitrogen) at $37^{\circ} \mathrm{C}$ and $5 \% \mathrm{CO}_{2}$ atmosphere for 48 hours. Adherent cells were detached from the flask with $0.25 \%(\mathrm{v} / \mathrm{v})$ trypsin in $1 \mathrm{mM}$ EDTA (Gibco-Invitrogen) at $37^{\circ} \mathrm{C}$ for $7-10$ minutes. Detached cells were suspended in RPMI medium supplemented with $10 \%$ heat-inactivated fetal bovine serum (Gibco-Invitrogen), and the cell suspension was used for coculture assay.

\section{Bioassay for IL-8 activity in AGS gastric epithelial cells}

AGS cell suspensions were seeded at a density of $1.0 \times 10^{5}$ cells $/ \mathrm{mL}(20,000$ cells per well) in a volume of $200 \mu \mathrm{L}$ per well of a 96-well flat-bottomed tissue culture plate (Nunclon D) and preincubated as described previously. After 24 hours of incubation, the culture supernatant was replaced with 200 $\mu \mathrm{L}$ of fresh RPMI. Cells were exposed to $5 \%(\mathrm{v} / \mathrm{v})$ conditioned media alone or in combination with $3 \times 10^{7}$ colonyforming unit (CFU)/mL viable H. pylori ATCC 43503 (6.0 $\times 10^{6} \mathrm{CFU}$ per well with a multiplicity of infection of 300 ). The assay plate was incubated under $5 \% \mathrm{CO}_{2}$ at $37^{\circ} \mathrm{C}$ for 24 hours, and cell culture supernatants were collected by centrifugation at $125 \times \mathrm{g}$ for 7 minutes at $4^{\circ} \mathrm{C}$. The IL- 8 level in the culture supernatant was determined using a Quantikine Human IL-8 Immunoassay Kit (R\&D Systems, Minneapolis, $\mathrm{MN}$ ) according to the manufacturer's instructions.

\section{Cell viability assay}

Cell viability was tested by Trypan blue dye exclusion (Gibco-Invitrogen). Briefly, cell suspensions were mixed with $0.4 \mathrm{w} / \mathrm{v}$ trypan blue solution (1:1) and visually examined for the inclusion or exclusion of dye. Trypan blue stains nonviable cells and is excluded by viable cells. The number of total cells and stained cells were counted on a hemocytometer under an inverted microscope within a $1 \mathrm{~mm}^{2}$ area. The percentage of viable cells was calculated from the ratio of viable cells over total cells. 


\section{H. pylori growth inhibition by lactobacilli Disc diffusion method}

IL-8-inhibitory strains of lactobacilli were tested for antagonistic activity against $H$. pylori ATCC 43504 as follows. Sterile $6 \mathrm{~mm}$ membrane discs (Whatman, Maidstone, UK) were soaked in cell-free Lactobacillus-conditioned media at room temperature for at least 1 hour. H. pylori was applied to Columbia blood agar, and discs containing Lactobacillus-conditioned media were subsequently placed atop the agar. After incubation under microaerophilic conditions at $37^{\circ} \mathrm{C}$ for 72 hours, a clear zone around a disc was scored positive for antagonistic activity against the growth of $H$. pylori. A disc soaked with MRS broth was used as a negative control. Conditioned medium from L. salivarius T59, our laboratory strain that can antagonize the growth of H. pylori, was used as a positive control. The experiments were performed in triplicate.

\section{Spot-overlay method}

Antagonism of $H$. pylori growth was also assessed using a spot-overlay method as previously described..$^{20}$ Briefly, Lactobacillus spp. were cultured anaerobically at $37^{\circ} \mathrm{C}$ for 24 hours in brain heart infusion (BHI) broth (Oxoid), spotted onto BHI agar, and incubated anaerobically at $37^{\circ} \mathrm{C}$ for 48 hours. The spotted plate of Lactobacillus was then overlaid with soft agar $(0.75 \%$ agar) containing 72 -hour culture of H. pylori in BHI broth supplemented with $10 \%$ horse serum at a final concentration of $1 \times 10^{8} \mathrm{CFU} / \mathrm{mL}$. The overlain plate was incubated microaerophilically at $37^{\circ} \mathrm{C}$ for 72 hours. A clear zone around each spot of Lactobacillus was scored as positive. L. salivarius T59 was included as a positive control for inhibition of $H$. pylori. The experiments were performed in triplicate.

\section{Statistical analysis}

All experiments were performed three times in triplicate, and the results were reported as mean value with standard deviation (SD). The data were analyzed using the Student's $t$-test with one-tailed distribution and were considered statistically significant at a $P$ value $<0.05$.

\section{Results}

\section{IL-8 production by $H$. pylori-stimulated AGS gastric epithelial cells and immunomodulatory effects of gastric biopsy-derived Lactobacillus spp.}

Twenty-six Lactobacillus spp. isolated from gastric biopsies of dyspeptic patients were selected on the basis that they are able to inhibit TNF production in LPS-activated THP-1 monocytoid cells but do not stimulate TNF production in high magnitude by themselves ${ }^{18}$ (Table 1, Figure 1). These isolates were tested for the ability to inhibit IL-8 production in $H$. pylori-stimulated AGS gastric epithelial cells. AGS gastric epithelial cells secreted increased amounts ( $>15$-fold) of IL-8 after 24 hours of coincubation with $H$. pylori compared with cells exposed to bacterial media (MRS) alone. Cell-free conditioned media of five Lactobacillus spp. significantly inhibited IL-8 production in various magnitudes, whereas those of 14 lactobacilli did not (Figure 2). Conditioned media of these 19 lactobacilli did not have cytotoxic effects on AGS cells, as the percentage of viable cells in each sample was $>80 \%$. Conditioned media from seven lactobacilli (L. casei B13, L.gasseri XB68, L. salivarius B8 and B73, and L. plantarum B64, B67, and B87) killed more than $35 \%$ of AGS cells, resulting in $>80 \%$ of IL-8 suppression (data not shown).

The ability of the five IL-8-suppressing Lactobacillus spp. (L. plantarum $\mathrm{B} 90$ and XB7, L. salivarius $\mathrm{B} 60$, L. rhamnosus B103, and L. casei or L. paracasei B106) to modulate IL-8 production in the presence or absence of $H$. pylori is shown in Figure 3. In the absence of H. pylori, the conditioned media of these five Lactobacillus spp. did not significantly stimulate IL- 8 production.

\section{IL-8-inhibitory Lactobacillus spp. did not inhibit the growth of $\mathrm{H}$. pylori}

To investigate whether IL-8-suppressive activity of these five Lactobacillus spp. resulted from the inhibition of $H$. pylori growth, we tested the antagonism of $H$. pylori growth by using the LCM disc diffusion and spot-overlay methods. It was found that these lactobacilli did not inhibit the growth of H. pylori, as shown in Table 2.

\section{Discussion}

The human gastrointestinal microbiota are an important source of potential probiotics for human use. The human stomach harbors diverse microbial flora, including lactobacilli, as determined by $16 \mathrm{~S}$ rRNA gene sequencing, ${ }^{21}$ and different Lactobacillus spp. have been cultivated from gastric biopsies of healthy humans. ${ }^{22,23}$ These gastric lactobacilli could be promising candidate probiotics for $H$. pylori-associated diseases. Although our gastric Lactobacillus spp. were isolated from dyspeptic patients, they have the ability to inhibit TNF production from LPSactivated THP-1 monocytoid cells. ${ }^{18}$ In the present study, 
Table I Tumor necrosis factor (TNF)-inhibitory Lactobacillus spp. isolated from gastric biopsies of dyspeptic patients

\begin{tabular}{|c|c|c|c|c|c|}
\hline \multirow[t]{2}{*}{ Code } & \multirow[t]{2}{*}{ Species $^{a}$} & \multirow[t]{2}{*}{ Source $^{b}$} & \multicolumn{2}{|c|}{ TNF value $(\mathrm{pg} / \mathrm{mL})^{\mathrm{c}}$} & \multirow{2}{*}{$\begin{array}{l}\% \text { TNF } \\
\text { suppression }^{d}\end{array}$} \\
\hline & & & No LPS & With LPS & \\
\hline $\mathrm{BI} 3$ & L. casei & Mild gastritis & $27.59 \pm 1.70$ & $502.41 \pm 48.13$ & $16.45^{*}$ \\
\hline XB68 & L. gasseri & Normal & - & $331.05 \pm 82.13$ & $63.64 * * *$ \\
\hline B90 & L. plantarum & Normal & - & $667.85 \pm \mid 33.81$ & $47.32 *$ \\
\hline XB94 & L. gasseri & Normal & - & $662.83 \pm 83.72$ & $28.05^{*}$ \\
\hline BI06 & $\begin{array}{l}\text { L. casei or } \\
\text { L. paracasei }\end{array}$ & Normal & - & $598.00 \pm 179.26$ & $35.09 *$ \\
\hline B7 & L. plantarum & Gastritis & - & $322.40 \pm 248.35$ & $74.52 * *$ \\
\hline B8 & L. salivarius & Gastritis & $31.05 \pm 53.78$ & $102.67 \pm 60.48$ & $76.31 * * *$ \\
\hline B2I & L. salivarius & Gastritis & $218.38 \pm 3.31$ & $565.46 \pm 2.65$ & $47.47 * * *$ \\
\hline XB4I & L. gasseri & Gastritis & - & $959.62 \pm 124.16$ & $30.16^{*}$ \\
\hline XB45 & L. gasseri & Gastritis & $283.82 \pm 31.37$ & $495.33 \pm 20.82$ & $25.31 *$ \\
\hline B47 & L. salivarius & Gastritis & $183.20 \pm 180.17$ & $565.07 \pm 345.54$ & $55.34 *$ \\
\hline XB48 & L. gasseri & Gastritis & $136.55 \pm 26.22$ & $543.52 \pm 92.45$ & $18.05^{*}$ \\
\hline XB58 & L. gasseri & Gastritis & - & $436.48 \pm 66.48$ & $36.85^{*}$ \\
\hline B64 & L. plantarum & Gastritis & - & $173.49 \pm 118.69$ & $74.90 * *$ \\
\hline $\mathrm{B} 60$ & L. salivarius & Gastritis & $224.53 \pm 98.58$ & $359.24 \pm 61.67$ & $48.03^{*}$ \\
\hline B67 & L. plantarum & Gastritis & - & $382.86 \pm 157.58$ & $53.39 *$ \\
\hline B73 & L. salivarius & Gastritis & $151.43 \pm 19.18$ & $383.57 \pm 109.76$ & $53.30 * *$ \\
\hline XB77 & L. gasseri & Gastritis & $70.61 \pm 47.29$ & $609.78 \pm 40.00$ & $27.12^{*}$ \\
\hline B87 & L. plantarum & Gastritis & - & $588.54 \pm 96.42$ & $41.91 * *$ \\
\hline XB95 & L. gasseri & Gastritis & - & $1272.38 \pm 166.13$ & $24.76 * *$ \\
\hline XB96 & L. gasseri & Gastritis & - & $1 \mathrm{II} .16 \pm 72.73$ & $34.23 * * *$ \\
\hline $\mathrm{BIO3}$ & L. rhamnosus & Gastritis & - & $1033.51 \pm 27.97$ & $21.48 * * *$ \\
\hline XB7 & L. plantarum & Gastritis & - & $241.22 \pm 66.09$ & $57.23 * * *$ \\
\hline B23 & L. salivarius & Gastric ulcer & - & $340.53 \pm 87.06$ & $39.62 * *$ \\
\hline B36 & L. agilis & Gastric ulcer & - & $293.65 \pm 119.97$ & $62.76^{*}$ \\
\hline XB40 & L. gasseri & Gastric ulcer & - & $110.99 \pm 35.10$ & $82.4 I^{* *}$ \\
\hline
\end{tabular}

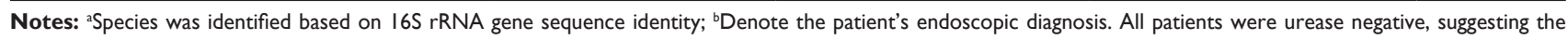
absence of Helicobacter pylori in the stomach; 'Data are reported as the mean value \pm standard deviation; - indicates TNF value below detection limit; ${ }^{\mathrm{d} T N F}$ suppression was calculated from the difference of TNF value of THP-I cells cocultured with MRS media control + LPS and LCM + LPS. Significantly different from control: ***P $<0.00$ I; $* * P<0.01 ; * P<0.05$.

Abbreviations: LPS, lipopolysaccharide; MRS, de Man, Rogosa, Sharpe.

we demonstrated that five gastric isolates of Lactobacillus spp. have the ability to inhibit IL-8 production from AGS gastric epithelial cells stimulated by $H$. pylori. This suggests that these lactobacilli secrete immunoregulatory factors known as immunomodulins,${ }^{24}$ which are potentially capable of inhibiting IL-8 production from their host. Previous reports have shown that viable $L$. bulgaricus or its culture supernatant inhibited IL-8 production in SGC-7901 gastric adenocarcinoma cells treated with $H$. pylori. ${ }^{25}$ In addition, live $L$. gasseri OLL2716 (LG21), as well as its spent culture supernatant, was reported to suppress $H$. pylori-induced IL-8 production from both MKN45 gastric epithelial cells and the gastric mucosa of H. pylori-infected patients. ${ }^{26}$ The fact that different strains of the same species of our gastric lactobacilli varied in their ability to suppress IL-8 production highlights the strain specificity of this inhibitory property. IL- 8 secreted by gastric epithelial cells of $H$. pylori-infected patients stimulates the migration of neutrophils and lymphocytes to the inflamed mucosa, resulting in more inflammatory pathology. ${ }^{2}$ Neutrophils and mononuclear cells recruited to patients' mucosa induce nitric oxide synthase to produce mutagenic nitric oxides that may result in DNA damage and subsequent apoptosis in the gastric mucosa. ${ }^{27}$ Therefore, our IL-8-inhibitory gastric Lactobacillus may be beneficial for the reduction of mucosal inflammation.

Probiotic Lactobacillus are known to suppress H. pyloriinduced IL-8 production in vitro by different mechanisms, such as the inhibition of the TLR 4 pathway, ${ }^{25}$ acid production, ${ }^{26,28}$ activation of suppressor of cytokine signaling, ${ }^{29}$ and inhibition of expression and function of the Cag type IV secretion system..$^{28}$ Our isolated Lactobacillus did not inhibit the growth of $H$. pylori as shown by either the disc diffusion or spot-overlay assays. In addition, IL-8 production was not affected by acidity, because the $\mathrm{pH}$ 


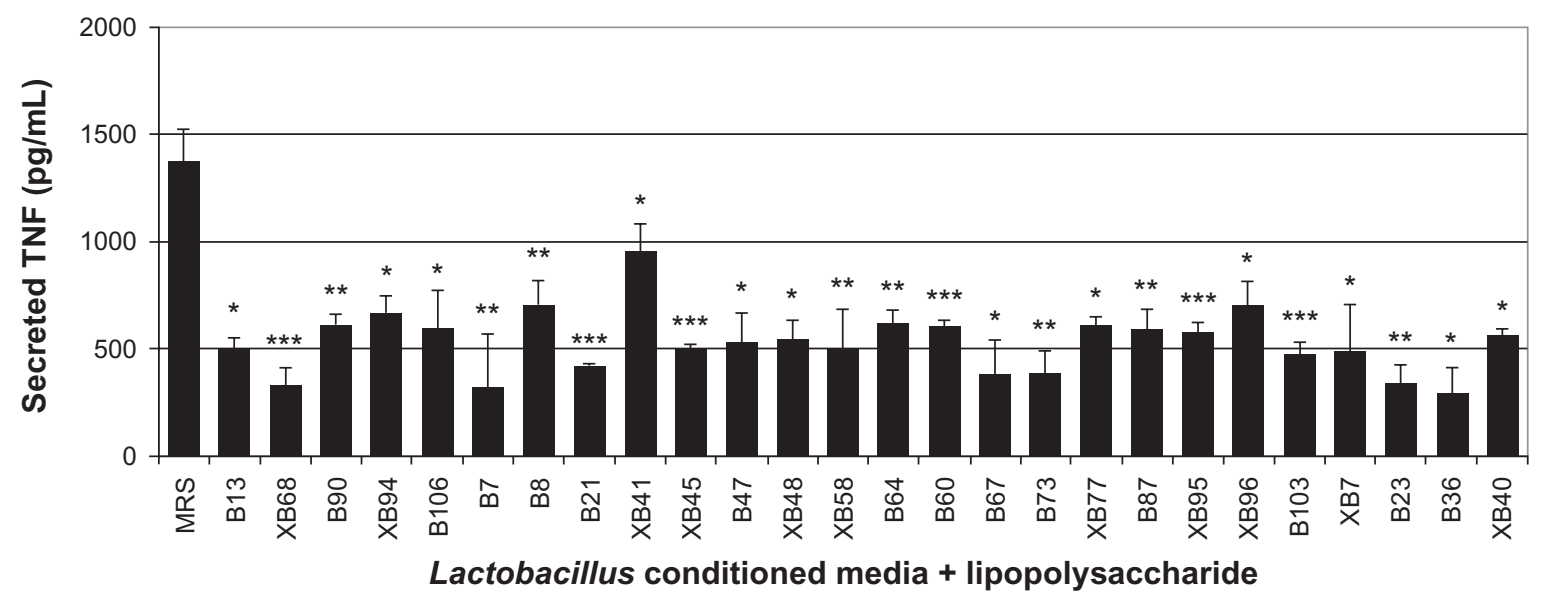

Figure I Effects of Lactobacillus conditioned media on TNF production in LPS-activated THP-I monocytoid cells.

Notes: TNF secretions were determined by human TNF enzyme-linked immunosorbent assay. The results are expressed as the mean of triplicate determinations. Significantly different from control: $* * * P<0.001 ; * * P<0.01 ; * P<0.05$. Error bars indicate standard deviations.

Abbreviations: LPS, lipopolysaccharide; MRS, de Man, Rogosa, Sharpe; TNF, tumor necrosis factor.

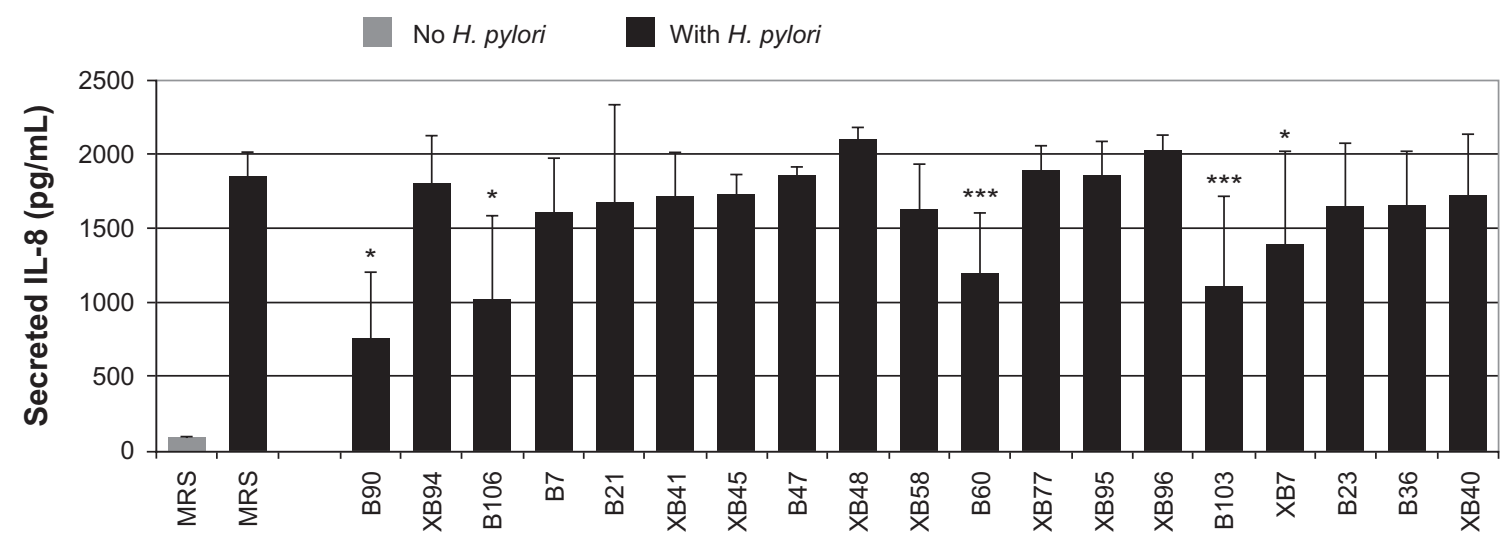

Lactobacillus conditioned media

Figure 2 Effects of Lactobacillus-conditioned media from 19 gastric isolates on IL-8 production from Helicobacter pylori-stimulated AGS gastric epithelial cells.

Notes: AGS cells were coincubated with Lactobacillus-conditioned media and H. pylori. IL-8 secretions were determined by human IL-8 enzyme-linked immunosorbent assay. The results are expressed as the mean of triplicate determinations representative of three independent experiments. Significantly different from control: $* * * P<0.00 \mathrm{I}$; $* P<0.05$. Error bars indicate standard deviations.

Abbreviations: IL-8, interleukin-8; MRS, de Man, Rogosa, Sharpe.

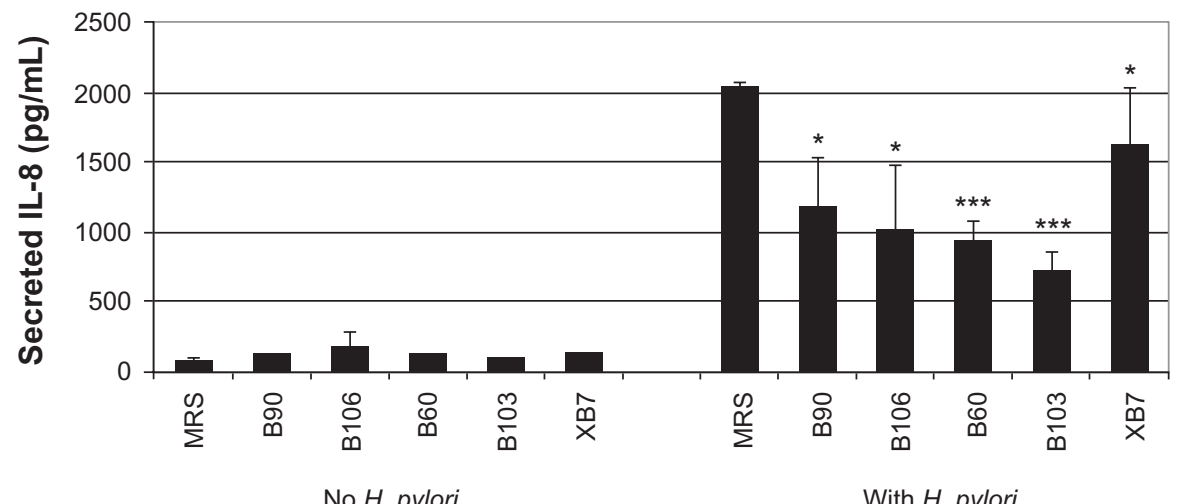

No H. pylori

With H. pylori

Figure 3 Immunomodulatory effects of Lactobacillus B90-, BI06-, B60-, BI03-, and XB7-conditioned media on AGS gastric epithelial cells.

Notes: Bioassays for IL-8 production were performed with or without Helicobacter pylori stimulation. The results are expressed as the mean of triplicate determinations representative of three independent experiments. Significantly different from control: $* * * P<0.001 ; * P<0.05$. Error bars indicate standard deviations.

Abbreviations: IL-8, interleukin-8; MRS, de Man, Rogosa, Sharpe. 
Table 2 Interleukin-8-inhibitory Lactobacillus spp. are not antagonistic to Helicobacter pylori growth

\begin{tabular}{lll}
\hline & $\begin{array}{l}\text { Disc diffusion } \\
\text { assay }\end{array}$ & $\begin{array}{l}\text { Spot-overlay } \\
\text { assay }\end{array}$ \\
\hline L. salivarius T59a & + & + \\
L. casei or L. paracasei BI06 & - & - \\
L. plantarum B90 & - & - \\
L. plantarum XB7 & - & - \\
L. rhamnosus B103 & - & - \\
L. salivarius B60 & - & - \\
\hline
\end{tabular}

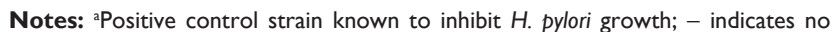
growth inhibition; + indicates growth inhibition.

levels of conditioned media of IL-8-inhibitory and IL-8noninhibitory Lactobacillus spp. were approximately equal (data not shown).

Of the five IL-8-suppressive lactobacilli identified in the present study, L. salivarius is considered indigenous (autochthonous) to humans, whereas the remaining four species are considered transient (allochthonous).$^{30}$ We have identified indigenous and transient Lactobacillus species with anti-inflammatory activity. These isolates are potential candidates for the treatment of $H$. pylori-induced gastric illness and deserve further characterization of their probiotic mechanisms.

\section{Acknowledgments}

This work was supported by the Thailand Research Fund through the Royal Golden Jubilee PhD Program (Grant No. PHD/0100/2549) to TT and the Thai Government Research Budget to ST. We thank Jennifer K Spinler for reviewing the manuscript.

\section{Disclosure}

The authors declare no conflicts of interests in this work.

\section{References}

1. Kusters JG, van Vliet AH, Kuipers EJ. Pathogenesis of Helicobacter pylori infection. Clin Microbiol Rev. 2006;19(3):449-490.

2. Robinson K, Argent RH, Atherton JC. The inflammatory and immune response to Helicobacter pylori infection. Best Pract Res Clin Gastroenterol. 2007;21(2):237-259.

3. Noach LA, Bosma NB, Jansen J, et al. Mucosal tumor necrosis factor-alpha, interleukin-1 beta, and interleukin-8 production in patients with Helicobacter pylori infection. Scand J Gastroenterol. 1994;29(5):425-429.

4. Harris PR, Mobley HL, Perez-Perez GI, et al. Helicobacter pylori urease is a potent stimulus of mononuclear phagocyte activation and inflammatory cytokine production. Gastroenterology. 1996;111(2): 419-425.

5. Yamaoka Y, Kita M, Kodama T, et al. Helicobacter pylori cagA gene and expression of cytokine messenger RNA in gastric mucosa. Gastroenterology. 1996;110(6):1744-1752.
6. Lindley I, Aschauer H, Seifert JM, et al. Synthesis and expression in Escherichia coli of the gene encoding monocyte-derived neutrophilactivating factor: biological equivalence between natural and recombinant neutrophil-activating factor. Proc Natl Acad Sci U S A. 1988;85(23):9199-9203.

7. Baggiolini M, Walz A, Kunkel SL. Neutrophil-activating peptide-1/ interleukin 8, a novel cytokine that activates neutrophils. J Clin Invest. 1989;84(4):1045-1049.

8. Crabtree JE, Wyatt JI, Trejdosiewicz LK, et al. Interleukin-8 expression in Helicobacter pylori infected, normal, and neoplastic gastroduodenal mucosa. J Clin Pathol. 1994;47(1):61-66.

9. Ando T, Kusugami K, Ohsuga M, et al. Interleukin-8 activity correlates with histological severity in Helicobacter pylori-associated antral gastritis. Am J Gastroenterol. 1996;91(6):1150-1156.

10. Cavallaro LG, Egan B, O'Morain C, Di Mario F. Treatment of Helicobacter pylori infection. Helicobacter. 2006;11 Suppl 1: 36-39.

11. Vakil N, Megraud F. Eradication therapy for Helicobacter pylori. Gastroenterology. 2007;133(3):985-1001.

12. Kwon JH, Lee DH, Song BJ, et al. Ten-day sequential therapy as firstline treatment for Helicobacter pylori infection in Korea: a retrospective study. Helicobacter. 2010;15(2):148-153.

13. Megraud F. H pylori antibiotic resistance: prevalence, importance, and advances in testing. Gut. 2004;53(9):1374-1384.

14. Mahachai V, Thong-Ngam D, Noophun P, et al. Efficacy of clarithromycin-based triple therapy for treating Helicobacter pylori in Thai non-ulcer dyspeptic patients with clarithromycin-resistant strains. J Med Assoc Thai. 2006;89 Suppl 3:S74-S78.

15. Sirimontaporn N, Thong-Ngam D, Tumwasorn S, Mahachai V. Ten-day sequential therapy of Helicobacter pylori infection in Thailand. Am J Gastroenterol. 2010;105(5):1071-1075.

16. Kamiji MM, de Oliveira RB. Non-antibiotic therapies for Helicobacter pylori infection. Eur J Gastroenterol Hepatol. 2005;17(9):973-981.

17. O'Connor A, Gisbert J, O'Morain C. Treatment of Helicobacter pylori infection. Helicobacter. 2009;14 Suppl 1:46-51.

18. Panpetch W. Detection of Lactobacillus in the Stomach of Dyspeptic Patients and its Role in the Suppression of TNF Production in Vitro. Thailand: Graduate School, Chulalongkorn University; 2008.

19. Taweechotipatr M, Iyer C, Spinler JK, et al. Lactobacillus saerimneri and Lactobacillus ruminis: novel human-derived probiotic strains with immunomodulatory activities. FEMS Microbiol Lett. 2009; $293 ; 1: 65-72$.

20. Spinler JK, Taweechotipatr M, Rognerud CL, et al. Human-derived probiotic Lactobacillus reuteri demonstrate antimicrobial activities targeting diverse enteric bacterial pathogens. Anaerobe. 2008;14(3): 166-171.

21. Bik EM, Eckburg PB, Gill SR, et al. Molecular analysis of the bacterial microbiota in the human stomach. Proc Natl Acad Sci U S A. 2006; 103(3):732-737.

22. Roos S, Engstrand L, Jonsson H. Lactobacillus gastricus sp. nov., Lactobacillus antri sp. nov., Lactobacillus kalixensis sp. nov. and Lactobacillus ultunensis sp. nov., isolated from human stomach mucosa. Int J Syst Evol Microbiol. 2005;55(Pt 1):77-82.

23. Ryan KA, Jayaraman T, Daly P, et al. Isolation of lactobacilli with probiotic properties from the human stomach. Lett Appl Microbiol. 2008;47(4):269-274.

24. Guarner F, Bourdet-Sicard R, Brandtzaeg P, et al. Mechanisms of disease: the hygiene hypothesis revisited. Nat Clin Pract Gastroenterol Hepatol. 2006;3(5):275-284.

25. Mannick EE, Bravo LE, Zarama G, et al. Inducible nitric oxide synthase, nitrotyrosine, and apoptosis in Helicobacter pylori gastritis: effect of antibiotics and antioxidants. Cancer Res. 1996;56(14):3238-3243.

26. Zhou C, Ma FZ, Deng XJ, et al. Lactobacilli inhibit interleukin-8 production induced by Helicobacter pylori lipopolysaccharideactivated Toll-like receptor 4. World J Gastroenterol. 2008;14(32): 5090-5095. 
27. Tamura A, Kumai H, Nakamichi N, et al. Suppression of Helicobacter pylori-induced interleukin- 8 production in vitro and within the gastric mucosa by a live Lactobacillus strain. J Gastroenterol Hepatol. 2006; 21(9):1399-1406.

28. Ryan KA, O'Hara AM, van Pijkeren JP, et al. Lactobacillus salivarius modulates cytokine induction and virulence factor gene expression in Helicobacter pylori. J Med Microbiol. 2009;58(Pt 8):996-1005.
29. Lee JS, Paek NS, Kwon OS, Hahm KB. Anti-inflammatory actions of probiotics through activating suppressor of cytokine signaling (SOCS) expression and signaling in Helicobacter pylori infection: a novel mechanism. J Gastroenterol Hepatol. 2010;25(1):194-202.

30. Reuter G. The Lactobacillus and Bifidobacterium microflora of the human intestine: composition and succession. Curr Issues Intest Microbiol. 2001;2(2):43-53.

International Journal of Interferon, Cytokine and Mediator Research

\section{Publish your work in this journal}

The International Journal of Interferon, Cytokine and Mediator Research is an international, peer-reviewed, open-access, online journal. The focus of the journal is to publish original research, reports, editorials, reviews and commentaries on all aspects of interferon, cytokine and mediators of inflammation from laboratory science to therapeutic indications and clinical studies. The manuscript management system is completely online and includes a very quick and fair peer-review system, which is all easy to use. Visit http://www.dovepress.com/testimonials.php to read real quotes from published authors.

Submit your manuscript here: http://www.dovepress.com/international-journal-of-interferon-cytokine-and-mediator-research-journal 